Yeshiva University, Cardozo School of Law

LARC @ Cardozo Law

Articles

Faculty

1997

\title{
The Ethics of Genetic Research on Sexual Orientation
}

Udo Schuklenk

Edward Stein

Benjamin N. Cardozo School of Law, estein2@yu.edu

Jacinta Kerin

William Byne

Follow this and additional works at: https://larc.cardozo.yu.edu/faculty-articles

Part of the Law Commons

\section{Recommended Citation}

Udo Schuklenk, Edward Stein, Jacinta Kerin \& William Byne, The Ethics of Genetic Research on Sexual Orientation, 27 Hastings Center Report 6 (1997).

Available at: https://larc.cardozo.yu.edu/faculty-articles/401

This Article is brought to you for free and open access by the Faculty at LARC @ Cardozo Law. It has been accepted for inclusion in Articles by an authorized administrator of LARC @ Cardozo Law. For more information, please contact larc@yu.edu. 


\section{The Ethics of Genetic Research on Sexual Orientation}

by Udo Schüklenk, Edward Stein, Jacinta Kerin, and William Byne

Research into the genetic component of some complex behaviors often causes controversy, depending on the social meaning and significance of the behavior under study. Research into sexual orientation-simplistically referred to as "gay gene" research-is an example of research that provokes intense controversy. This research is worrisome for many reasons, including the fact that it has been used to harm lesbians and gay men. Many homosexual people have been forced to undergo "treatments" to change their sexual orientation. Others chose to undergo them to escape discrimination and social disapprobation. But there are other reasons to worry about such research. The very motivation for seeking an "origin" of homosexuality reveals homophobia. Moreover, such research may lead to prenatal tests that claim to predict for homosexuality. For homosexual people who live in countries with no legal protections these dangers are particularly serious.

$\mathrm{R}$ esearch on the origins of sexual orientation has received much public attention in recent years, especially findings consistent with the notion of relatively simple links between genes and sexual orientation. Investigation into the causes of same-sex attraction has, however, been ongoing for more than one hundred years. ${ }^{1}$ Claims that such inquiry is dangerous, especially in certain social and political climates, are as old as the research itself. In this paper, we show that such genetic research in particular gives rise to serious ethical issues.

\section{Genetic Research}

Sientific research on sexual orientation has taken $\checkmark$ many forms. One early idea was to find evidence of a person's sexual orientation in such bodi-

Udo Schüklenk, Edward Stein, Jacinta Kerin, and William Byne, "The Ethics of Genetic Research on Sexual Orientation," Hastings Center Report 27, no. 4 (1997): 6-13. ly features as amount of facial hair, size of external genitalia, and the ratio of shoulder width to hip width. Today's seemingly more sophisticated morphological research looks instead at neuroanatomical structures. Such inquiry usually assumes sexual orientation is a trait with two forms, one typically associated with males and the other typically associated with females. Researchers who accept this assumption expect particular aspects of an individual's brain or physiology to conform to either a male type that causes sexual attraction to women (shared by heterosexual men and lesbians) or a female type that causes sexual attraction to men (shared by heterosexual women and gay men). This assumption is scientifically unsupported and there are alternatives to it.

Another early approach was to find evidence of a person's sexual orientation in his or her endocrine system. The idea was that gay men would have less androgenic hormones (the so-called male-typical hormones) or more estrogenic hormones (the socalled female-typical sex hormones) than straight men and that lesbians would have more androgenic 
and less estrogenic sex hormones than straight women. However, an overwhelming majority of studies failed to demonstrate any correlation between sexual orientation and adult hormonal constitution. ${ }^{2}$ According to current hormonal theories of sexual orientation, lesbians and gay men were exposed to atypical hormone levels early in their development. Such theories draw heavily on the observation that, in rodents, hormonal exposure in early development exerts organizational influences on the brain that determine the balance between male and female patterns of mating behaviors in adulthood. Extrapolating from behaviors in rodents to psychological phenomena in humans is, however, quite problematic. In rodents, a male who allows himself to be mounted by another male is counted as homosexual, while a male that mounts another male is considered heterosexual. This model defines sexual orientation in terms of specific postures and behaviors. In contrast, in the human case, sexual orientation is defined not by what "position" one takes in sexual intercourse but by one's pattern of erotic responsiveness and the sex of one's preferred sex partner.

Although early sex researchers reported that homosexuality runs in families, careful studies of this hypothesis are only beginning to be done. Several studies suggest that male homosexuality runs in families, ${ }^{3}$ but they are not helpful in distinguishing between genetic and environmental influences because most related individuals share both genes and environmental variables. Further disentanglement of genetic and environmental influences requires adoption studies.

The only heritability study of male homosexuality that includes an adoption component is the highly publicized study of Bailey and Pillard. ${ }^{4}$ The study suggests a significant environmental contribution to the development of sexual orientation in men in addition to a moderate genetic influence. This study assessed sexual orientation not only in the identi- cal and fraternal twins, but also in the nontwin biological brothers and the unrelated adopted brothers of the gay men who volunteered for the study. The concordance rate for identical twins ( 52 percent) was much higher than the concordance rate for the fraternal twins (22 percent). These concordance rates show that the environment must play a significant role in sex orientation because approximately half of the monozygotic twin pairs were discordant for sexual orientation despite sharing both their genes and familial environments. The higher concordance rate in the identical twins is consistent with a genetic effect because identical twins share all of their genes while fraternal twins, on average, share only half. Genes cannot, however, explain the remaining results of this study. In the absence of a significant environmental influence, the incidence of homosexuality among the adopted brothers of gay men should be equal to the rate of homosexuality in the general population, which recent studies place at somewhere between 2 and 5 percent. The observed concordance rate was 11 percent (two and five times higher than expected given the estimates); this suggests a major environmental contribution. Further, no genetic explanation can account for the fact that the concordance rate for homosexuality among nontwin brothers was about the same whether or not they were genetically related (the rate for homosexuality among nontwin biological brothers was 9 percent; among adopted brothers it was 11 percent).

When all the data from the twin study are considered, it appears that sexual orientation is the result of a combination of both genetic and environmental influences. Further, the combined effect of genetic and environmental influences might not simply be their sum; these factors could interact in a nonadditive or synergistic manner. In fact, recent heritability studies consistently find that almost half of the identical twin pairs are discordant for sexual orientations even though they share the same genes and similar familial environments. This finding underscores how little we know about the origins of sexual orientation.

Of all the recent biological studies, the genetic linkage study by Dean Hamer's group is the most conceptually complex. This study presents statistical evidence that genes influencing sexual orientation may reside in the q28 region of the $\mathrm{X}$ chromosome. Females have two X chromosomes, but they pass a copy of only one to a son. The theoretical probability of two sons receiving a copy of the same $\mathrm{Xq} 28$ from their mother is thus 50 percent. Hamer found that of forty pairs of gay siblings, thirtythree instead of the expectę twenty had received the same Xq28 region from their mother. Hamer's finding is often misinterpreted as showing that all sixty-six men from these thirtythree pairs shared the same Xq28 sequence. In fact, all he showed was that each member of the thirty-three concordant pairs shared his Xq28 region with his brother but not with any of the other sixty-four men. No single specific $\mathrm{Xq}_{2} 8$ sequence was common to all sixty-six men.

There are several problems with Hamer's study. First, a Canadian research team has been unable to duplicate the finding using a comparable experimental design. ${ }^{6}$ Second, Hamer confined his search to the $\mathrm{X}$-chromosome on the basis of family interviews, which seems to reveal a disproportionately high number of male homosexuals on the mothers' side of the family. Women might, however, be more likely to know details of family medical history, rendering these interviews less than objective in terms of directing experimental design. ${ }^{7}$ Third, one of Hamer's coauthors has expressed serious concerns about the methodology of the study. ${ }^{8}$ Fourth, there is some question about whether Hamer's results, correctly interpreted, are statistically significant. His conclusions rest on the assumption that the rate of homosexuality in the population at large (the base rate of homosexuality) is two percent. If the base rate is actually four percent 
or higher, then Hamer's results are not statistically significant. A leading geneticist argues that Hamer's own data support the four percent estimate.?

To understand what is at issue here, it is useful to contrast three models of the role genes might play necessarily many intervening pathways between a gene and a behavior and even more between a gene and a pattern that involves both thinking and behaving. For the term "gay gene" to have a clear meaning, one needs to propose that a particular gene, perhaps through a hormonal mechanism, organizes the brain specifically to support the desire to have sex with people of the same sex. No one has, however, presented evidence in support of such a simple and direct link between genes and sexual orientation.

in sexual orientation. ${ }^{10}$ According to the "permissive effect model," genes or other biological factors influence the neural substrate on which sexual orientation is inscribed by formative experience. On this view, genetic factors might also delimit the period during which experience can affect a person's sexual orientation. According to the "indirect effect model," genes code for (or other biological factors influence) temperamental or personality factors that influence how one interacts with and shapes one's environment and formative experiences. On this view, the same gene (or set of genes) might predispose to homosexuality in some environments, to heterosexuality in others, and have no effect on sexual orientation in others. Finally, according to the "direct effect model," genes (or other biological factors) influence the brain structures that mediate sexual orientation. Hamer, LeVay, and most other researchers seem to favor the direct model.

One version of the direct model involves talk of "gay genes." It is important to remember that genes in themselves cannot directly specify any behaviors or psychological phenomena; rather, a gene directs a particular pattern of RNA synthesis that in turn specifies the amino acid sequence of a particular protein that may influence behavior. There are temporary societies, lesbians, gay men, and bisexuals are subject to widespread discrimination and social disapprobation. Against this background, we are concerned about the particularly gruesome history of the use of such research. Many homosexual people have been forced to undergo "treatments" to change their sexual orientation, while others have "chosen" to undergo them in order to escape societal homophobia. All too often, scientifically questionable "therapeutic" approaches destroyed the lives of perfectly healthy people. "Conversion therapies" have included electroshock treatment, hormonal therapies, genital mutilation, and brain surgery. "We are concerned about the negative ramifications of biological research on sexual orientation, especially in homophobic societies. In Germany, some scholars have warned of the potential for abuse of such genetic research, while others have called for a moratorium on such research to prevent the possible abuse of its results in homophobic societies. These warnings should be taken seriously.

We are concerned that people conducting research on sexual orientation work within homophobic frameworks, despite their occasional claims to the contrary. A prime example is the German obstetrician Günter Dörner, whose descriptions of homosexuality ill-conceal his heterosexism. Dörner writes about homosexuality as a "dysfunction" or "disease" based on "abnormal brain development." He postulates that it can be prevented by "optimizing" natural conditions or by "correcting abnormal hormonal concentrations prenatally" (emphasis added). ${ }^{12}$ Another example is provided by psychoanalyst Richard Friedman, who engages in speculation about nongay outcome given proper therapeutic intervention. ${ }^{13}$ Research influenced by homophobia is likely to result in significantly biased accounts of human sexuality; further, such work is more likely to strengthen and perpetuate the homophobic attitudes on which it is based. 


\section{Sexual Orientation Research} Is Not Value Neutral

Gurthermore, we question whether those who research sexual orientation can ever conduct their work in a value-neutral manner. One might think that the majority of American sex researchers treats homosexuality not as a disease, but rather as a variation analogous to a neutral polymorphism. To consider whether or not this is the case, one must look at the context in which interest in sexual orientation arises. Homophobia still exists to some degree in all societies within which sexual orientation research is conducted. The cultures in which scientists live and work influence both the questions they ask and the hypotheses they imagine and explore. Given this, we believe it is unlikely that the sexual orientation research of any scientist (even one who is homosexual) will escape some taint of homophobia. This argument is importantly different from one which claims that objective research can be used unethically in discriminatory societies. The latter logic implies that what should be questioned is the regulation of the application of technology, not the development of the technology in the first place. While we do provide arguments for questioning the efficacy of such regulations should they be developed, our deeper concerns are directed toward the institutional and social structures that constrain sex research. Attention to these contextual details shows that research into sexual orientation is different from research into most other physical/behavioral variations. Since sexual orientation is the focus of intense private and public interest, relevant inquiry cannot be studied independently of societal investment. It is naive to suggest that individual researchers might suddenly find themselves in the position of neutral inquirers. Social mores both constrain and enable the ways in which an individual's research is focused.

We are not claiming that all researchers are homophobic to some degree whether or not they are aware of it. Nor are we talking about the implicit or explicit intentions of individual sexual orientation researchers. Rather we are seeking to highlight that the very motivation for seeking the "origin" of homosexuality has its source within social frameworks that are pervasively homophobic. Recognition that scientific projects are constituted by, and to some degree complicit in, social structures does not necessarily entail that all such science should cease. At the very least, however, it follows that sexual orientation research and its use should be subject to critique. Such a critique will call into question the claim that, by treating homosexuality as a mere variation of human behavior, researchers are conducting neutral investigations into sexual orientation.

\section{Predicting Sexual Orientation in Utero}

WVe are also worried that an amniocentesis-like test will be developed that claims to detect genes or hormonal levels that might predispose for homosexuality. This concern may seem paradoxical, since the development of such a test seems to rely on the truth of the direct model of sexual orientation, which we describe as scientifically unsupported. Yet the development of such a test is, in principle, compatible with either the direct or indirect genetic model of sexual orientation. While current scientific results favor neither model, it is conceivable that future studies might clarify this impasse. Even evidence for the indirect model might inform the creation of a genetic screening technique that purports to influence sexual orientation in a given environment. Thus we are concerned that tests which do no more than suggest a predisposition for homosexuality would be favorably received in homophobic societies. If prospective parents believe they are able to predict the sexual orientation of a fetus by using a prenatal screening technique, it is possible that they would choose to abort a fetus that seemed to be "homosexually predisposed."
In many countries, the preference for male versus female offspring leads to the abortion of female fetuses. This preference is clearly connected to sexism operating at a societal level. In such instances, science is subverted to serve the interests of discriminatory societies. Thus, discrimination can be institutionalized through genetic screening techniques.

Moreover, tests can be both developed and well received even if they are based on bad science. People might make use of genetic screening procedures that are supposed to select for heterosexual children even if such procedures did not work. This is partly for the general reason that the public can, in various ways, be lead to accept unsound scientific procedures. More specifically, potential users of sexual-orientation-selection procedures will have a difficult time assessing the efficacy of such procedures for at least three reasons. First, since some children turn out to be heterosexual even without the use of such a procedure, many parents who make use of it will believe that the procedure has worked, even though the procedure has done nothing. Second, many people take a long time to come to grips with their sexual orientation. Parents who made use of such a procedure might think that it had been successful, but only because their child had not yet figured out her or his sexual orientation. Third, because some lesbians, gay men, and bisexuals hide their sexual orientation, many parents will think that their attempt at selecting their child's sexual orientation has worked when in fact it has not. Further, if a lesbian, gay man, or bisexual knows that his or her parents used such a procedure, this would increase the likelihood that the person would hide his or her sexual orientation from them. For these reasons, such a procedure is likely to appear to work even if it does not. Given the appearance that such procedures work, as well as the widespread prejudice and discrimination against lesbians, gay men, and bisexuals, some people will attempt to select the sexual orienta- 
tion of their children. This would likely engender and perpetuate attitudes that lesbians and gay men are undesirable and not valuable, policies that discriminate against lesbians and gay men, and the very conditions that give rise to such attitudes and policies. ${ }^{14}$

\section{Replies to These Concerns}

iven the wide-ranging abuse of $\mathbf{I}_{\text {the results of biological research }}$ on sexual orientation in the past, it is not surprising that people realize that ethical justifications for this work are needed. Some researchers say their work can provide answers to centuryold questions surrounding religious propositions that homosexuality is abnormal or unnatural. ${ }^{15}$ However, biological research on the causes of sexual orientation cannot possibly provide answers to questions concerning the nature and normality of homosexuality. As we will go on to illustrate, the only senses in which homosexuality can be said to be, or fail to be, natural or normal are of no ethical relevance. Given that some scientists claim their empirical research can provide answers to normative questions, the danger of committing a naturalistic fallacy in this context is very real.

Normativity of Naturalness and Normality. Why is there a dispute as to whether homosexuality is natural or normal? We suggest it is because many people seem to think that nature has a prescriptive normative force such that what is deemed natural or normal is necessarily good and therefore ought to be. Everything that falls outside these terms is constructed as unnatural and abnormal, and it has been argued that this constitutes sufficient reason to consider homosexuality worth avoiding. ${ }^{16}$ Arguments that appeal to "normality" to provide us with moral guidelines also risk committing the naturalistic fallacy. The naturalistic fallacy is committed when one mistakenly deduces from the way things are to the way they ought to be. For instance, Dean Hamer and colleagues commit this error in their Science article when they state that "it would be fundamentally unethical to use such information to try to assess or alter a person's current or future sexual orientation, either heterosexual or homosexual, or other normal attributes of human behavior." ${ }^{17}$ Hamer and colleagues believe that there is a major genetic factor contributing to sexual orientation. From this they think it follows that homosexuality is normal, and thus worthy of preservation. Thus they believe that genetics can tell us what is normal, and that the content of what is normal tells us what ought to be. This is a typical example of a naturalistic fallacy.

Normality can be defined in a number of ways, but none of them direct us in the making of moral judgments. First, normality can be reasonably defined in a descriptive sense as a statistical average. Appeals to what is usual, regular, and/or conforming to existing standards ultimately collapse into statistical statements. For an ethical evaluation of homosexuality, it is irrelevant whether homosexuality is normal or abnor$\mathrm{mal}$ in this sense. All sorts of human traits and behaviors are abnormal in a statistical sense, but this is not a sufficient justification for a negative ethical judgment about them. Second, "normality" might be defined in a functional sense, where what is normal is something that has served an adaptive function from an evolutionary perspective. This definition of normality can be found in sociobiology, which seeks biological explanations for social behavior. There are a number of serious problems with the sociobiological project. ${ }^{18}$ For the purposes of this argument, however, suffice it to say that even if sociobiology could establish that certain behavioral traits were the direct result of biological evolution, no moral assessment of these traits would follow. To illustrate our point, suppose any trait that can be reasonably believed to have served an adaptive function at some evolutionary stage is normal. Some questions arise that exemplify the problems with deriving normative conclusions from descriptive science. Are traits that are perpetuated simply through linkage to selectively advantageous loci less "normal" than those for which selection was direct? Given that social contexts now exert "selective pressure" in a way that nature once did, how are we to decide which traits are to be intentionally fostered?

Positions holding the view that homosexuality is unnatural, and therefore wrong, also inevitably develop incoherencies. They often fail to explicate the basis upon which the line between natural and unnatural is drawn. More importantly, they fail to explain why we should consider all human-made or artificial things as immoral or wrong. These views are usually firmly based in a nonempirical, prescriptive interpretation of nature rather than a scientific descriptive approach. They define arbitrarily what is natural and have to import other normative assumptions and premises to build a basis for their conclusions. For instance, they often claim that an entity called "God" has declared homosexuality to be unnatural and sinful. ${ }^{19}$ Unfortunately, these analyses have real-world consequences. In Singapore, "unnatural acts" are considered a criminal offence, and "natural intercourse" is arbitrarily defined as "the coitus of the male and female organs." A recent High Court decision there declared oral sex "unnatural," and therefore a criminal offence, unless it leads to subsequent reproductive intercourse.

Historical Evidence. In response to some of the ethical concerns about biological research on sexual orientation, some people have appealed to previous research on homosexuality that has not been used to the detriment of homosexuals. For example, Timothy Murphy invokes the work of Evelyn Hooker, which arguably provided evidence for the "normality" of homosexuals. ${ }^{20}$ However, historical examples are often disanalogous to present-day biological research. Hooker's small-scale study, in fact, had nothing to do with the origins of sexual orientation. Rather, she sought to discover whether or not 
homosexual people were "well-adapted" (by assessing the degree to which their daily practices conformed with that of "normal" Americans). Showing that nonbiological research has not been used unethically does not show that biological research will be used ethically. It is important to discern which sorts of historical events can be considered relevant to the debate concerning the implications and applications of research on sexual orientation.

Another defense of genetic research on sexual orientation, offered by Simon LeVay, suggests that psychological and sociological research is even more dangerous. LeVay bases his argument on the assertion that, for ideological reasons, the Nazis did not generally consider homosexuality to be innate or a sign of degeneracy, but rather that they thought homosexuality was spread by seduction. ${ }^{21}$ This is historically not true. The Nazis were as supportive of genetic research as they were of any other type of research designed to support the elimination of homosexuality. ${ }^{22}$ Even if LeVay's assertions were historically correct, however, they would not provide any support (ethical or otherwise) for genetic research. Arguing that one type of research is ethically problematic does not legitimize the other; indeed, it only provides further reason to question the whole enterprise.

U.S.-Specific Arguments. In the United States, several scholars and lesbian and gay activists have argued that establishing a genetic basis for sexual orientation will help make the case for lesbian and gay rights. The idea is that scientific research will show that people do not choose their sexual orientations and therefore they should not be punished or discriminated against in virtue of them. This general argument is flawed in several ways. ${ }^{23}$ First, we do not need to show that a trait is genetically determined to argue that it is not amenable to change at will. This is clearly shown by the failure rates of conversion "therapies." ${ }^{24}$ These failures establish that sexual orientation is resistant to change, but they do not say anything about its ontogeny or etiology. Sexual orientation can be unchangeable without being genetically determined. There is strong observational evidence to support the claim that sexual orientation is difficult to change, but this evidence is perfectly compatible with nongenetic accounts of the origins of sexual orientations. More importantly, we should not embrace arguments that seek to legitimate homosexuality by denying that there is any choice in sexual preference because the implicit premise of such arguments is that if there was a choice, then homosexuals would be blameworthy.

Relatedly, arguments for lesbian and gay rights based on scientific evidence run the risk of leading to impoverished forms of lesbian and gay rights. Regardless of what causes homosexuality, a person has to decide to publicly identify as a lesbian, to engage in sexual acts with another woman, to raise children with her same-sex lover, or to be active in the lesbian and gay community. It is when people make such decisions that they are likely to face discrimination, arrest, or physical violence. It is decisions like these that need legal protection. An argument for lesbian and gay rights based on genetic evidence is impotent with respect to protecting such decisions because it focuses exclusively on the very aspects of sexuality that might not involve choices.

Another version of this argument focuses on the specifics of U.S. law. According to this version, scientific evidence will establish the immutability of sexual orientation, which, according to one current interpretation of the Equal Protection Clause of the Fourteenth Amendment of the U.S. Constitution, is one of three criteria required of a classification if it is to evoke heightened judicial scrutiny. While this line of argument has serious internal problems, ${ }^{25}$ such an argument, like a good deal of American bioethical reasoning, has limited or no relevance to the global context. Since the results of the scientific research are not confined within American borders, justifications that go beyond U.S. legislation are required.

The same sort of problem occurs in other defenses of sexual orientation research that discuss possible ramifications in U.S.-specific legislative terms. For instance, Timothy Murphy claims that, even if a genetic probe predictive of sexual orientation were available, mandatory testing would be unlikely. ${ }^{26} \mathrm{He}$ bases this claim on the fact that in some states employment and housing discrimination against homosexual people is illegal. In many countries, however, the political climate is vastly different, and legal anti-gay discrimination is widespread. And there is evidence that scientific research would be used in a manner that discriminates against homosexuals. ${ }^{27}$ As already mentioned, in Singapore, homosexual sex acts are a criminal offense. The Singapore Penal Code sections 377 and $377 \mathrm{~A}$ threaten sentences ranging from two years to life imprisonment for homosexual people engaging in same-sex acts. Not coincidentally, in light of our concerns, a National University of Singapore psychiatrist recently implied that "pre-symptomatic testing for homosexuality should be offered in the absence of treatment, ${ }^{28}$ thereby accepting the idea that homosexuality is something in need of a cure.

Genetic Screening. Several attempts to defend sexual orientation research against ethical concerns related to the selective abortion of "pre-homosexual" fetuses have been made. It has been claimed that this sort of genetic screening will not be- 
come commonplace because "diagnostic genetic testing is at present the exception rather than the rule." ${ }^{29}$ While this may indeed be true in the U.S., it has far more to do with the types of tests currently offered than with a reluctance on the part of either the medical profession or the reproducing public to partake of such technology. For example, the types of tests available are diagnostic for diseases and are offered on the basis of family history or specific risk factors. The possibility of tests that are supposed to be (however vaguely) predictive of behavioral traits opens genetic technology to a far greater population, especially when the traits in question are undesired by a largely prejudiced society.

Furthermore, it has been claimed that the medical profession would not advocate such a test that does not serve "important state interests" (p. 341). This argument not only ignores the existence of homophobia among individuals within medicine, ${ }^{30}$ it assumes also that public demand for genetic testing varies predominantly according to medical advice. However, should such a test become available, the media hype surrounding its market arrival would render its existence common knowledge, which, coupled with homophobic bias, would create a demand for the test irrespective of its accuracy and of any kind of state interest. Furthermore, this argument ignores the fact that genetic screening for a socially undesirable characteristic has already been greeted with great public demand in countries such as India, where abortion on the basis of female sex is commonplace, irrespective of its legality. ${ }^{31}$ Techniques to select the sexual orientation of children, if made available, might well be widely utilized. ${ }^{32}$

Some have argued that orientation-selection techniques involving genetic screening will not succeed because environmental factors influencing sexual orientation would elude genetic screening. ${ }^{33}$ While there are such environmental factors, we are still concerned about the potential ef- fects of the availability of orientationselection techniques, even if they fail to work. Further, if environmental factors are identified, their modification could be defended on the same grounds as the elimination of "gay genes." In fact, behavior modification techniques have been, and continue to be, used to prevent homosexuality in children with "gender identity disorder" (that is, "sissies" and "tom boys"). ${ }^{34}$

It has also been claimed that if homosexual people themselves made use of orientation-selection techniques (whether to ensure homosexual or heterosexual offspring), the charge that such testing is inherently homophobic becomes "paradoxical." ${ }^{35}$ However, just as the fact that homosexual people conduct scientific research on sexual orientation does not show that such research is ethically justifiable, the fact that some homosexuals might use such techniques would not prove that the technology does not serve to discriminate. To illustrate this point, consider that in a society like India in which widespread discrimination against women exists, there are many pragmatic reasons why one might prefer a male child. We would not argue, however, that prenatal sex selection is no longer discriminatory against females because women sometimes seek abortions for the purpose of having male offspring. Similarly, in societies with entrenched homophobia, a heterosexual child might be preferable for reasons that might appear most salient to homosexuals themselves in lieu of the discrimination they have encountered. The use of a technology by people against whom it may discriminate (even if they attempt to use it to their benefit) does not establish its neutrality. It does, however, highlight the pervasive biases within a given society that should be addressed directly rather than be fostered with enabling technology. Discriminated-against users of discriminatory technology might have a variety of motives, none of which necessarily diffuse the charge of bias.
The Value of Knowing the Truth. Finally, various scholars appeal to the value of the truth to defend research on sexual orientation in the face of ethical concerns. Scientific research does, however, have its costs and not every research program is of equal importance. Even granting that, in general, knowledge is better than ignorance, not all risks for the sake of knowledge are worth taking. With respect to sexual orientation, historically, almost every hypothesis about the causes of homosexuality led to attempts to "cure" healthy people. History indicates that current genetic research is likely to have negative effects on lesbians and gay men, particularly those living in homophobic societies. ${ }^{36}$

\section{A Global Perspective}

$\mathrm{H}$ omosexual people have in the past suffered greatly from societal discrimination. Historically, the results of biological research on sexual orientation have been used against them. We have analyzed the arguments offered by well-intentioned defenders of such work and concluded that none survive philosophical scrutiny. It is true that in some countries in Scandinavia, North America, and most parts of Western Europe, the legal situation of homosexual people has improved, but an adequate ethical analysis of the implications of genetic inquiry into the causes of sexual orientation must operate from a global perspective. Sexual orientation researchers should be aware that their work may harm homosexuals in countries other than their own. It is difficult to imagine any good that could come of genetic research on sexual orientation in homophobic societies. Such work faces serious ethical concerns so long as homophobic societies continue to exist. Insofar as socially responsible genetic research on sexual orientation is possible, it must begin with the awareness that it will not be a cure for homophobia and that the ethical status of lesbians and gay men does not in any way hinge on its results. 


\section{References}

1. Rüdiger Lautmann, ed., Homosexualität: Handbuch der Theorie und Forschungsgeschichte (Campus Verlag: Frankfurt am Main, 1993); Vern Bullough, Science in the Bedroom: The History of Sex Research (Basic Books: New York, 1994).

2. Heino Meyer-Bahlburg, "Psychoendocrine Research on Sexual Orientation: Current Status and Future Options," Progress in Brain Research 71 (1984): 37597.

3. For example, Richard Pillard and James Weinrich, "Evidence for a Familial Nature of Male Homosexuality," Archives of General Psychiatry 43 (1986): 808-12.

4. J. Michael Bailey and Richard Pillard, "A Genetic Study of Male Sexual Orientation," Archives of General Psychiatry 48 (1991): 1089-96.

5. Dean Hamer et al., "A Linkage Between DNA Markers on the X Chromosome and Male Sexual Orientation," Science 261 (1993): 321-27.

6. G. Rice, C. Anderson, N. Risch, and G. Ebers, "Male Homosexuality: Absence of Linkage to Microsatellite Markers on the $\mathrm{X}$ Chromosome in a Canadian Study," presented at the 21st Annual Meeting of the International Academy of Sex Research, 1995, Provincetown. Mass. This presentation is discussed in E. Marshall, "NIH 'Gay Gene’ Study Questioned,” Science 268 (1995): 1841.

7. Evan Balaban, quoted in V. D'Alessio, "Born to be Gay?" New Scientist (28 September 1996): 32-35.

8. Marshall, "NIH's 'Gay Gene' Study Questioned," p. 1841.

9. Neil Risch, Elizabeth Squires-Wheeler, and Bronya Keats, "Male Sexual Orientation and Genetic Evidence," Science 262 (1993): 2063-65.

10. William Byne, "Biology and Sexual Orientation: Implications of Endocronological and Neuroanatomical Research," in Comprehensive Textbook of Homosexuality, ed. R. Labaj and T. Stein (Washington, D.C.: American Psychiatric Press, 1996), pp. 129-46.

11. Jonathan Ned Katz, Gay American History (New York: Thomas Crowell, 1976), pp. 197-422.

12. Günter Dörner, "Hormone-dependent Brain Development and Neuroendocrine Prophylaxis," Experimental and Clinical Endocrinology 94 (1989): 4-22.
13. Richard C. Friedman, Male Homosexuality: A Contemporary Psychoanalytic Perspective (New Haven: Yale University Press, 1988), p. 20.

14. Edward Stein, "Choosing the Sexual Orientation of Children," Bioethics (1998), forthcoming.

15. Udo Schüklenk and Michael Ristow, "The Ethics of Research into the Causes of Homosexuality," Journal of Homosexuality 31, nos. 3, 4 (1996): 5-30.

16. Michael Levin, "Why Homosexuality Is Abnormal," Monist 67 (1984): 251-83.

17. Hamer et al., "A Linkage Between DNA Markers on the X Chromosome and Male Sexual Orientation,"p. 326.

18. Philip Kitcher, Vaulting Ambition: Sociobiology and the Quest for Human $\mathrm{Na}$ ture (Cambridge, Mass.: MIT Press, 1985).

19. Udo Schüklenk and David Mertz, "Christliche Kirchen und AIDS," in Die Lehre des Unheils, ed. Edgar Dahl (Hamburg: Carlsen, 1993), pp. 263-79 and 30912.

20. Timothy Murphy, "Abortion and the Ethics of Genetic Sexual Orientation Research," Cambridge Quarterly of Healthcare Ethics 4 (1995): 340-50, especially p. 347.

21. Simon LeVay, Queer Science: The Use and Abuse of Research on Homosexuality (Cambridge, Mass: MIT Press, 1996), pp. 38 and 113.

22. See, for example, Julius Deussen, "Sexualpathologie," in Fortschritte der Erbpathologie, Rassenhygiene und ihrer Grenzgebiete 2 (1939): 67-102. Interestingly, the British Eugenics Society showed a keen interest in the outcome of this research. Matthias Weber, Ernst Rüdin. Eine kritische Biographie (Berlin: Springer, 1993). See also Pauline M. H. Mazumdar, Eugenics, $\mathrm{Hu}$ man Genetics and Human Failings: The Eugenics Society, Its Sources and Its Critics in Britain (London: Routledge, 1992). We thank Professor Hans-Peter Kröner, Institute for Theory and History of Medicine, Westfälische Wilhelms-Universität Münster, for bringing this information to our attention.

23. Edward Stein, "The Relevance of Scientific Research Concerning Sexual Orientation to Lesbian and Gay Rights," Journal of Homosexuality 27 (1994): 269-308.

24. Charles Silverstein, "Psychological and Medical Treatments of Homosexuality," in Homosexuality: Research Implications for Public Policy, ed. J. C. Gonsiorek and J.
D. Weinrich (Newbury Park, Calif.: Sage, 1991), pp. 101-14.

25. Janet Halley, "Sexual Orientation and the Politics of Biology: A Critique of the New Argument from Immutability," Stanford Law Review 46 (1994): 503-68.

26. Murphy, "Abortion and the Ethics of Genetic Sexual Orientation Research," p. 341 .

27. Paul Billings, "Genetic Discrimination and Behavioural Genetics: The Analysis of Sexual Orientation," in Intractable Neurological Disorders, Human Genome, Research and Society, ed. Norio Fujiki and Darryl Macer (Christchurch and Tsukuba: Eubios Ethics Institute, 1993), p. 37; Paul Billings "International Aspects of Genetic Discrimination," in Human Genome Research and Society, ed. Norio Fujiki and Darryl Macer (Christchurch and Tsukuba: Eubios Ethics Institute, 1992), pp. 114-17.

28. L. C. C. Lim, "Present Controversies in the Genetics of Male Homosexuality," Annals of the Academy of Medicine Singapore 24 (1995): 759-62.

29. Murphy, "Abortion and the Ethics of Genetic Sexual Orientation Research," p. 341.

30. Kevin Speight, "Homophobia Is a Health Issue," Health Care Analysis 3 (1995): 143-48.

31. Kusum, "The Use of Prenatal Diagnostic Techniques for Sex Selection: The Indian Scene," Bioethics 7 (1993): 149-65.

32. Richard Posner, Sex and Reason (Cambridge, Mass.: Harvard University Press, 1992), p. 308.

33. Murphy, "Abortion and the Ethics of Genetic Sexual Orientation Research," p. 346. Indeed, the recently announced Environmental Genome Project launched by the $\mathrm{NIH}$ has begun with research on the interaction of genes and the environment.

34. See Richard Green, The 'Sissy Boy' Syndrome and the Development of Homosexuality (New Haven: Yale University Press, 1987); Phyllis Burke, Gender Shock: Exploding the Myths of Male and Female (New York: Anchor Books, 1996).

35. Murphy, "Abortion and the Ethics of Genetic Sexual Orientation Research," p. 343.

36. For further elaborations on this argument see Edward Stein, Udo Schüklenk, and Jacinta Kerin, "Scientific Research on Sexual Orientation," in Encyclopedia of Applied Ethics, ed. Ruth Chadwick (San Diego: Academic Press, 1997). 